PONTIFICIA UNIVERSIDADE CATOLICA DE MINAS GERAIS

A utilização da Terapia Fotodinâmica no tratamento de inflamação e infecção dos sacos anais de um cão: relato de caso

Núcleo Universitário Betim

Ana Paula Pacheco e Silva Bruna Aparecida Lima Gonçalves

Betim 2007

Ana Paula Pacheco e Silva Bruna Aparecida Lima Gonçalves 


\section{A utilização da Terapia Fotodinâmica no tratamento de inflamação e infecção dos sacos anais de um cão: relato de caso \\ Núcleo Universitário Betim}

Trabalho apresentado à disciplina Estágio
Supervisionado, da Escola de Medicina
Veterinária da Pontifícia Universidade
Católica de Minas Gerais

Betim 2007 


\title{
RESUMO
}

Este trabalho tem por objetivo relatar o tratamento de um cão diagnosticado com inflamação e infecção dos sacos anais utilizando-se apenas a terapia fotodinâmica (TFD) com led vermelho e uso do fotossensibilizador azul de metileno 0,01\%. Após duas sessões de TFD com intervalo entre elas de 48 horas o cão apresentou significativa melhora do quadro clinico não sendo necessário fazer uso de outros métodos convencionais de terapêutica. A terapia fotodinâmica mostrou-se eficaz para o tratamento clinico de inflamação e infecção dos sacos anais.

Palavras Chave: afecções dos sacos anais, terapia fotodinâmica, ledterapia

\begin{abstract}
This present article aims to describe the treatment of canine anal sac inflation and infection by Photodynamic-therapy (PDT). PDT was obtained by using a dye, blue metilen $0,01 \%$ and red light from a red LED light source. After two treatments, on every 48 hours, the dog present complete recovery from anal sac illness, without any other conventional drug administration. PDT showed to be an efficient in treat anal sac inflammation and infection.
\end{abstract}

Key words: anal sac infection, photodynamic-therapy, led -therapy 


\section{SUMÁRIO}

- INTRODUÇÃo

- REVISÃO DE LITERATURA

- AFECÇÕES DOS SACOS ANAIS

- Fisiopatologia

- $\quad$ Sinais predisponentes

- Achados do exame clinico

- Achados laboratoriais

- Diagnóstico diferencial

- Tratamento clinico

- Tratamento cirúrgico

- TERAPIA FOTODINÁMICA

- Substancias fotossensibilizantes

- Mecanismo de ação

- $\quad$ Fonte de luz

- Terapia fotodinâmica na veterinária

- MATERIAL E METODOS

- RESULTADO E DISCUSSÃO

- CONCLUSÃo

- REFERENCIAS BIBLIOGRAFICAS 


\section{INTRODUÇÃO}

A inflamação dos sacos anais é comum na clinica de pequenos animais. Ocorre principalmente em cães e raramente em gatos, sendo o seu tratamento teoricamente fácil de ser feito. Elas consistem em impactações, infecções, abscedações e neoplasias ${ }^{2,3,12,15}$. Os sacos anais são estruturas cutâneas anexas modificadas ${ }^{3}$.

A terapia fotodinâmica (TFD) é uma técnica de tratamento onde se faz uso de substâncias fotossensibilizantes que posteriormente são ativadas com luz de comprimento de onda especifico, esta técnica tem como finalidade causar a destruição celular e morte microbiana através da ação de produtos citotoxicos fotoativados $1,4,5,6,9,10,11,13,16,17$.

Este trabalho tem por objetivo relatar o tratamento de um cão diagnosticado com inflamação e infecção dos sacos anais utilizando apenas a terapia fotodinâmica com led vermelho e uso do fotossensibilizador azul de metileno $0,01 \%$.

\section{REVISÃO DE LITERATURA}

\subsection{AFECÇÕES DOSSACOS ANAIS}

\subsubsection{Fisiopatologia}

As afecções dos sacos anais ocorrem com mais freqüência nos cães e são menos comuns nos gatos ${ }^{3}$. Elas consistem em impactações, infecções, abscedações e neoplasias ${ }^{2,3,12,15}$. Os sacos anais são estruturas cutâneas anexas modificadas ${ }^{3}$. Eles estão pareados, situando-se entre as fibras do esfíncter anal, e são revestidos por epitélio escamoso, com glândulas sebáceas e apócrinas modificadas; neles são reservadas secreções dessas glândulas, que são expulsas por meio de ductos durante a defecação normal e excitação extrema ${ }^{3,15}$.

A saculite anal é comum e sua causa geralmente se deve a uma infecção ou obstrução do ducto ${ }^{3}$. A obstrução ductal leva a um super crescimento bacteriano, infecção e inflamação ${ }^{3}$. A inflamação potencializa as secreções, que vão servir como meio para o crescimento de bactérias ${ }^{3}$. Se a infecção ou a obstrução do ducto persistir poderá ocorrer uma fistulação, podendo esta tornar-se crônica ${ }^{3}$. Saculite anal também ocorre sem que ocorra obstrução do ducto, pela hipersecreção o que causa a compressão do saco ${ }^{3}$. A hipersecreção pode ser causada por mecanismos infecciosos, endócrinos, alérgicos, comportamentais, e idiopáticos ${ }^{3}$. Disfunção no mecanismo esfinctérico anal secundário a uma diarréia crônica, frouxidão anal, constipação e obesidade também podem contribuir para a retenção de secreções do saco anal e o desenvolvimento de saculite anal ${ }^{3,15}$. A função dos sacos anais ainda é desconhecida ${ }^{12}$.

\subsubsection{Sinais predisponentes}

A saculite anal pode ocorrer em qualquer idade, raça ou sexo; no entanto, ela é mais comum em cães de pequeno porte e toy (Poodle, Chihuahuas, Cockers e Springer Spaniels Ingleses) e é rara em gatos ${ }^{3,12,15}$. São menos comuns em Pastores Alemães e raças gigantes ${ }^{12}$. Em alguns animais ela pode estar associada a uma dermatite seborréica ou a outras dermatoses ${ }^{3}$.

Muitos animais apresentam histórico de diarréia ou fezes moles ou estro recente (1 
a 3 semanas) ${ }^{3}$. Eles evidenciam, geralmente, irritação anal; outras queixas incluem perseguição de cauda, descarga perianal fétida, dor ou sensibilidade e alteração comportamental ${ }^{3}$. Ocasionalmente ocorrem tenesmo, disquezia, constipação e hematoquezia ${ }^{3,15}$.

\subsubsection{Achados do exame clínico}

O exame físico das estruturas perianais mostra se a afecção do saco anal é unilateral ou bilateral ${ }^{2}$. Eritema, tumefação, dor e subseqüente ruptura e drenagem do saco agudamente infectado podem ocorrer 1 a $2 \mathrm{~cm}$ lateralmente ao ânus ${ }^{12}$. A palpação do tecido perianal durante exame retal pode identificar o saco anal aumentado, firme e, algumas vezes, dolorido ${ }^{3}$. Abscessos ou impactações podem fazer com que ele se rompa e crie uma lesão drenante ${ }^{3}$. A compressão digital da região pode expelir secreções normais( serosas, ligeiramente viscosas e granulares e amarelo-pálidas) ou anormais (cinza esbranquiçada, marrons, amarelas ou verdes, sanguinolentas, purulentas, arenosas, turvas, opacas) ${ }^{2,3,15}$.

Diagnostica-se impactação quando o saco fica distendido e levemente dolorido, não é comprimido facilmente ${ }^{3}$. As impactações tendem a se recidivar ${ }^{12}$. Já na inflamação do saco anal o animal apresenta dor moderada a severa durante a palpação, as secreções são líquidas, amareladas, tingidas de sangue ou purulentas ${ }^{3}$. Faz um diagnóstico de abscedação de saco anal quando ocorre distensão acentuada do saco com exsudato purulento, celulite de tecidos circundantes, eritema da pele sobrejacente, dor e febre $^{3}$. Os abscessos geralmente são unilaterais e o curso é curto ${ }^{12}$. As impactações e as infecções crônicas podem apresentar um curso prolongado ${ }^{12}$.

Apenas a história clínica e o exame físico são comumente suficientes para se dar o diagnóstico de afecção do saco anal ${ }^{2}$.

\subsubsection{Achados Laboratoriais}

As alterações hematológicas e bioquímicas séricas são inespecíficas ${ }^{3}$. Em caso de abscessos do saco anal, pode-se observar leucocitose com desvio à esquerda ${ }^{3}$. A citologia das secreções do saco anal revela resíduos celulares, grande número de leucócitos e muitas bactérias ${ }^{3}$. Recomenda-se fazer cultura e antibiograma do saco anal 3. A flora bacteriana normal do saco anal inclui pequeno número de micrococos, Escherichia coli, Streotococcus faecalis, e Staphylococcus spp. ${ }^{2,3,15}$. Já as bactérias encontradas nos sacos anais afetados incluem: S. faecalis, Clostidium perfringens, E. Coli, Proteus spp., Staphylococcus spp., micrococos e diftéróides ${ }^{2,3,12,15}$. A Malassezia pachydermatis é freqüentemente isolada dos sacos anais normais e anormais ${ }^{12}$.

\subsubsection{Diagnóstico Diferencial}

O diagnóstico diferencial para saculite anal são alergia por pulgas (decorrente de lambedura e mordedura), tumores perianais (causados por inchaço e ulceração), fístulas perianais, ou piodermatite da dobra caudal (resultado de abscedação e tratos drenantes) 3. O diferencial quanto a irritações anais ou perianais incluem saculite, dermatite, endoparasitas, fístulas perianais ou tumores ${ }^{3}$. Diagnósticos diferenciais quanto a inchaço perianal incluem hérnia perianal, neoplasias perianais, atresia anal, pitiose retal e tumores vaginais ${ }^{3}$. 


\subsubsection{Tratamento clínico}

O tratamento depende do estágio da afecção ${ }^{3}$. A maioria dos problemas em saco anal podem ser tratados clinicamente por meio de compressão manual, lavagem, antibióticos e alteração dietética ${ }^{3}$. Saculite ou impactação leve deve ser tratada por meio de compressão, lavagem, e infusão de preparado de antibiótico-corticosteróide dentro das glândulas ${ }^{2,3,12,15}$. Isso pode ser repetido de 5 a 7 dias ${ }^{12}$. Se os sacos anais se infectarem, pode-se acrescentar clorexina a $0,5 \%$ ou iodo-povidina a $10 \%$ em lavagens com jatos de solução salina ${ }^{2,3,12}$. Os antibióticos de escolha são as penicilinas, aminoglicosídeos e cloranfenicol ${ }^{2}$. Em casos crônicos, deve-se escolher antibióticos orais com base em resultados de antibiograma ${ }^{3}$. Os abscessos de saco anal devem ser lancetados, drenados e lavados com jato, juntamente com a administração de antibióticos orais apropriados ${ }^{2,3,15}$. Se leveduras estiverem envolvidas a irrigação com nistatina pode ser utilizada ${ }^{12}$.

Não é recomendável a cauterização excessiva dos sacos anais com agentes cáusticos como o nitrato de prata, tintura de iodo, e soluções contendo formalina ${ }^{15}$. A cauterização pode resultar numa necrose celular extensa, formação de pseudomembrana, encarceramento de microorganismos infecciosos subjacentemente a pseudomembrana, e formação de trajetos fistulosos com origem na parede do saco anal residual ${ }^{15}$.

\subsubsection{Tratamento cirúrgico}

Episódios recidivantes de compactação grave, saculite anal, abscessos, e adenocarcinomas do saco anal são indicações para a saculectomia anal ${ }^{12,15}$.

Falha na terapia clínica e suspeita de neoplasia são indicações para saculectomia anal ${ }^{3}$. Se persistir trato drenante após ruptura no saco anal, dever-se-á retardar a cirurgia até que se controle a inflamação ${ }^{3}$.

Deve-se remover ambos os sacos anais mesmo se somente um esteja acometido, para evitar uma segunda cirurgia ${ }^{3}$.

\subsection{TERAPIA FOTODINÁMICA}

O termo fotodinâmica surgiu em 1904 quando Von Tappeiner descreveu reações químicas com consumo de oxigênio após fotossensibilização em biologia ${ }^{1}$.

A terapia fotodinâmica (TFD) é uma técnica de tratamento onde se faz uso de substâncias fotossensibilizantes que posteriormente são ativadas com luz de comprimento de onda especifico, esta técnica tem como finalidade causar a destruição celular e morte microbiana através da ação de produtos citotóxicos fotoativados $1,4,5,6,9,10,11,13,16,17$. A luz ou a substancia sozinhas terão pouco ou nenhum efeito ${ }^{11}$. Os egípcios deram inicio a essa terapia, há mais de 4 mil anos atrás, através da ingestão de plantas e luz solar para tratar doenças como o vitiligo ${ }^{14}$. Mas essa técnica só começou a ser usada com sistemática cientifica a pouco tempo ${ }^{14}$.

A base da terapia fotodinâmica é a combinação de uma droga mais luz ${ }^{14}$. Uma substancia fotossensível é introduzida no paciente e se acumula nas células que se reproduzem rapidamente, então essas são irradiadas via laser ${ }^{14}$. A luz ativa a substancia gerando formas de oxigênio tóxicas que causam necrose ou afetam o 
diretamente o tumor, levando a cura do paciente ${ }^{14}$. A morte microbiana ocorre quando o corante (substancia fotossensibilizante) absorve a energia luminosa, provocando a produção de substancias altamente reativas, que vão causar danos ao microorganismo ou célula alvo ${ }^{17}$.

A TFD é usada no tratamento de vários tipos de doenças, mas é mais usada no combate ao câncer ${ }^{4,8,10}$. Ela é muito eficiente na redução bacteriana, fungica e na desativação de vírus principalmente em lesões localizadas, de pouca profundidade e com agente conhecido ${ }^{6,17}$. É um tratamento de baixo custo, com poucos efeitos colaterais e não há efeitos sistêmicos alem de não haver resistência bacteriana ${ }^{17}$. Embora a TFD tenha sido originalmente desenvolvida visando a terapia do câncer em suas diversas formas, tem ficado claro seu potencial no que concerne outras moléstias, como psoríase, degeneração macular da retina, condições autoimunes, arteriosclerose, remoção de verrugas na laringe, tratamento de moléstias fúngicas e destruição de infestações resistentes a tratamentos tradicionais à base de antibióticos ${ }^{6}$.

Nenhum efeito mutagênico sobre as células sadias tem sido reportado até o momento, o que amplia a segurança de aplicação dessa modalidade terapêutica, permitindo ainda repetição do tratamento no caso de recorrência ou mesmo de grandes lesões ${ }^{6}$.

O emprego da TFD em lesões primárias envolvendo a pele tem-se reportado um alto índice de casos bem sucedidos, combinadas a excelentes resultados cosméticos ${ }^{6}$.

\subsubsection{Substâncias Fotossensibilizantes}

A primeira geração de drogas usadas na TFD, a base de derivados hematoporfirínicos, teve inicio com Schwartz na década de $50{ }^{14}$. Na década de 60 Lipson investigou o acumulo preferencial deles em tumores, implantados em camundongos e ratos observando assim que a incidência de luz levava a regressão da doença ${ }^{14}$. Após esses estudos Lipson obteve sucesso no tratamento do câncer de mama em uma mulher usando a mesma técnica empregada nos camundongos, marcando assim o inicio do uso da TFD no tratamento de câncer ${ }^{14}$. A partir da década de 70 iniciaramse vários estudos com derivados porfirínicos para uso em TFD ${ }^{14}$.

A primeira geração de drogas usadas na TFD, baseada em misturas de derivado porfirínicos, tem se mostrado bastante eficiente no tratamento de tumores de diversas origens sejam eles malignos ou não ${ }^{6}$.

As substâncias fotossensibilizadoras utilizadas possuem estrutura similar à clorofila e à hemoglobina sendo então moléculas com um anel heterocíclico ${ }^{17}$. Tais substâncias absorvem luz com elevada eficiência, em alguma região do espectro visível, sendo por isso que alguns desses compostos conseguem induzir ou participar de reações fotoquímicas ${ }^{6}$. Portanto, tais substâncias devem ser absorvidas numa região próxima ao local onde se aplicara infra-vermelho ${ }^{14}$.

Certas substâncias têm sido empregadas como agentes terapêuticos, como é o caso do azul de metileno e da violeta de genciana (cristal violeta), dentre muitos outros ${ }^{6}$.

As substancias fotossensibilizadoras devem ter as seguintes propriedades:

- Características foto físicas favoráveis;

- baixa toxicidade no escuro (baixa citotoxicidade);

- fotossensibilidade não prolongada;

- simplicidade na formulação, reprodutibilidade e alta estabilidade do formulado, que em geral é mantido seco,sendo necessário que o medico adicione aqua ou 
soro fisiológico;

- farmacocinética favorável;

- facilidade no manuseio sintético que permita efetuar modificações para melhorar as propriedades desejadas;

- facilidade de obtenção em escala industrial a baixo custo e com boa reprodutibilidade;

- facilidade de analise total dos componentes da formula;

- alta afinidade e penetração no tecido doente e pouca no tecido saudável ${ }^{6,14,17}$.

É importante que o medicamento atenda a todas essas propriedades gerais para que seja considerado uma droga viável e eficaz na sua ação terapêutica ${ }^{14}$.

Um outro processo que a substância fotossensibilizadora sofre é o de fotobranqueamento, que é causado por modificações na estrutura da molécula devido a reações paralelas ${ }^{14}$. O foto-branqueamento significa que a molécula sofrera uma reação e seu produto não absorvera mais luz no comprimento de onda de incidência, deixando então de exercer seu papel terapêutico ${ }^{14}$.

As primeiras propriedades fotofisicas in vitro observadas em uma molécula candidata a ser usada na TFD são:

- forte absorção de luz na região acima de $650 \mathrm{~nm}$, onde a luz apresenta maior penetração no tecido;

- alto rendimento quântico de estado tripleto;

- alto rendimento quântico de oxigênio singleto;

- baixo rendimento de reação de foto-branqueamento do cromóforo ${ }^{14}$.

\subsubsection{Mecanismo de Ação}

O mecanismo de ação da TFD funciona da seguinte forma o paciente recebe uma determinada dose da substancia fotossensibilizadora que vai se acumular no local desejado, logo em seguida irradia-se o tecido com luz visível ${ }^{9}$. O agente fotossensibilizante então absorve o fóton que vem da fonte de luz e seus elétrons passam para um estado de excitação ${ }^{5,10,17}$. Quando há um substrato, como por exemplo o oxigênio, o agente fotossensibilizador ao voltar ao seu estado natural transfere para ele a sua energia, formando assim espécies reativas de oxigênio (EROs) que podem causar danos em microrganismos via oxidação irreversível de componentes celulares $5,9,10,17$

A geração de EROs pode ocorrer através de dois mecanismos conhecidos como tipo I e tipo II ${ }^{9}$. No tipo I, a substância fotossensibilizadora transfere seus elétrons para o oxigênio no seu estado fundamental gerando assim um radical superoxido ${ }^{4,6,9,10}$. Esse radical por sua vez, pode reagir com o peróxido de hidrogênio, presente no meio celular, gerando assim o radical hidroxila que é um potente agente oxidante ${ }^{4,6,9,10}$. Já no mecanismo tipo II, a substancia transfere energia para o oxigênio no estado fundamental e gera uma espécie extremamente reativa que é o oxigênio singleto ${ }^{4,6,9,10}$. O oxigênio singleto é como são conhecidos os três estados eletronicamente excitados imediatamente superiores ao oxigênio molecular no estado fundamental ${ }^{4,6,10}$. Segundo a Teoria do Orbital Molecular, o oxigênio no estado fundamental possui na sua configuração eletrônica dois elétrons desemparelhados nos orbitais moleculares degenerados ${ }^{6}$. Tais elétrons tendem a ter o mesmo spin de forma a produzir multiplicidade máxima e com isso um estado de mais baixa energia ${ }^{6}$. E é essa a razão de o oxigênio molecular em seu estado fundamental ser um tripleto ${ }^{6}$. O oxigênio 
singleto pode efetuar varias reações com substratos biológicos podendo levar a interrupção de processos biológicos ${ }^{14}$. Entretanto, não existe ainda certeza de que ele seja o responsável pela fototoxicidade, uma vez que ele causa a formação de radicais livres ${ }^{14}$.

\subsubsection{Fonte de Luz}

A melhor fonte de radiação tem sido aquela que por um baixo custo forneça a maior quantidade de luz possível no máximo de absorção da substancia fotossensibilizante, sem efeitos térmicos significativos ${ }^{6}$.

As primeiras fontes de luz usadas foram lâmpadas convencionais, acoplava-se um filtro colorido para que se pudesse selecionar determinados comprimentos de onda ${ }^{17}$.

A fotoativação, a principio, pode ser feita por qualquer fonte de luz visível, desde que esta possua características espectrais especificas, alta potência de saída e máxima absorção pela substância fotossensibilizante ${ }^{1}$. A maioria das fontes de radiação empregadas são lasers ${ }^{6}$.

$\mathrm{Na}$ medicina humana os laseres têm sido usados como adjuvante nos tratamentos convencionais, devido aos seus efeitos destrutivos contra microrganismos ${ }^{17}$. A vantagem é que sua luz pode ser direcionada por cabos de fibra óptica ${ }^{11}$. Permitindo que se direcione a luz para o tecido afetado sem expor o saudável ${ }^{11}$. A dose de luz é medida em joules por centímetro quadrado sendo esse o produto da intensidade da luz pelo tempo ${ }^{11}$. Os lasers de baixa intensidade não levam ao aumento de temperatura das estruturas afetadas e quando são associados a um corante (substância fotossensibilisadora), geralmente exógeno, podem levar a morte microbiana ${ }^{17}$. Além da facilidade em fazer sua associação com uma substância fotossensível ${ }^{17}$.

\subsubsection{Terapia fotodinâmica na veterinária}

Um dos primeiros relatos da TFD em medicina veterinária descreveu o uso da hematoporfirina no tratamento de 8 variados tumores em cães e 3 em gatos ${ }^{5}$. Os animais receberam $5 \mathrm{mg} / \mathrm{Kg}$ endovenoso 48 horas antes do tratamento luminoso, o tempo de exposição variava de 20 a 30 minutos ${ }^{5}$. Os tumores tratados eram osteossarcoma, carcinoma de células escamosas, melanoma, fibrosarcoma, tumor de glândula sebácea e metástase de carcinoma prostático ${ }^{5}$. $86 \%$ das lesões foram responsivas, contudo os osteossarcomas foram o menos responsivos 5 . Os efeitos adversos foram fotossensibilização cutânea e eritema ${ }^{5}$. O uso da TFD também é relatado em gatos com FeLV ${ }^{5}$.

\section{MATERIAL E METODOS}

Um cão macho, da raça Poodle, com 7 anos de idade foi atendido no dia oito de março de 2007, na Clínica Veterinária Professor Israel com sintomatologia de lambedura e mordedura na região da cauda, relutância em sentar-se, fricção do ânus no chão. O histórico clínico era de dois episódios anteriores de afecção dos sacos anais nos dias 13 de novembro de 2003 e 02 de setembro 2005, respectivamente.O tratamento instituído nessas datas constituiu em drenagem, limpeza com solução salina 0,9\% associado a terapia anti microbiana: Metronidazol e espiramincina (Stormogyl $\left.{ }^{\circledR}\right)^{\mathrm{b}}$ posologia de acordo com a bula e Prednisona $\left(\text { Meticorten }^{\circledR}\right)^{\mathrm{a}}$ na dose antiinflamatória 
$1 \mathrm{mg} / \mathrm{Kg}$, ambos uma vez ao dia durante 7 dias, com melhora significativa do quadro.

Ao exame clínico o animal apresentava um estado geral bom, mucosas ${ }^{1}$ normocrômicas e linfonodos sem alterações. A região perianal estava inflamada, edemaciada. A região direita ao orifício anal estava bastante aumentada de volume (Figura 1).

No mesmo dia foi realizada tricotomia da região afetada, drenagem, limpeza com salina $0,9 \%$ e realização da Terapia Fotodinâmica, que consistiu na utilização de azul de metileno $0,01 \%$ (quimiolux-hipopharma) depositado na região. Como fonte de luz, utilizou-se um aparelho de LED, ( MM Optics - FISIOLED) o qual emite luz vermelha com comprimento de onda de 630 nanômetros. O Tempo de exposição foi de 2 minutos, o que corresponde para este aparelho, uma fluência de $28 \mathrm{~J} / \mathrm{cm} 2$ (Figura 2).

Foi realizado somente mais uma sessão após 48 horas. Observou-se melhora significativa do quadro (Figura 3).

\section{RESULTADO E DISCUSSÃO}

A utilização do corante de azul de metileno, como agente fotossensibilizador, associado ao led vermelho mostrou-se eficaz para o tratamento de inflamação e infecção dos sacos anais. O animal apresentou melhora significativa do quadro clínico.

O animal após a segunda sessão de TFD já não apresentava desconforto, nem alteração de comportamento, a região não estava edemaciada, nem dolorida, com isso não houve necessidade da realização de outra sessão. $O$ proprietário mostrou-se satisfeito com o resultado.

A Terapia fotodinâmica é uma alternativa de tratamento para afecções recidivantes tratadas anteriormente com medicamentos convencionais, é comprovadamente eficaz para obtenção de efeito antimicrobiano sobre bactérias e não causa danos aos tecidos saudáveis.

\section{CONCLUSAO}

A terapia fotodinâmica mostrou-se eficaz para o tratamento clinico de inflamação do saco anal em cães.

1 aeticorten ${ }^{\circledR}$-Shering-Plough; ${ }^{\mathrm{b}}$ Stomorgyl ${ }^{\circledR}$-Merial 


\section{REFERÊNCIAS BIBLIOGRÁFICAS}

1- BAKOS, R. M. et al. Terapêutica fotodinâmica com ácido delta-aminolevulínico em neoplasias queratinocíticas superficiais. An. Bras. Dermatol., Rio de Janeiro, v. 78, n. 2, 2003.

2- ETTINGER, Stephen J. Tratado de medicina interna veterinária: moléstias do cão e do gato. 5.ed. Ed.Guanabara Koogan. Rio de Janeiro, RJ, 2004.v.2, p.1335-1336.

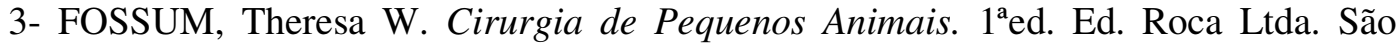
Paulo, SP, 2002. p. 381-389.

4- LUCENA, E. G., et al. Terapia fotodinâmica de neovascularização de coróide por degeneração macular relacionada à idade com benzoporfirina (verteporfirina). Arq. Bras. Oftalmol., São Paulo, v. 63, n. 6, 2000.

5- LUCROY, MICHAEL D.; PONTIFÍCIA UNIVERSIDADE CATÓLICA DE MINAS GERAIS. Departamento de Medicina Veterinária. Veterinary photodynamic therapy. Journal Of The American Veterinary Medical Association, v.216 ,n.11 ,p.1745-1751, jun. 2000.

6- MACHADO, Antonio E. H.. Terapia Fotodinâmica: princípios, potencial de aplicação e perspectivas. Quím. Nova., São Paulo, v. 23, n. 2, 2000.

7- MAIA, H. S. et al. Terapia fotodinâmica com verteporfirina em neovascularização coroidiana subfoveal secundária a coriorretinopatia serosa central: relato de caso. Arq. Bras. Oftalmol., São Paulo, v. 68, n. 4, 2005.

8- NICOLAI, Renata A.; PONTIFÍCIA UNIVERSIDADE CATÓLICA DE MINAS GERAIS. Departamento de Medicina Veterinária. Estudo preliminar da absorção do 5ala tópico em mucosa vaginal de cadela.. Revista da Faculdade de Medicina Veterinária de Valença, Valença, v.1, n.2, p. 10-14, jan. 2000.

9- RIBEIRO, J. N. et al. Determinação do mecanismo de destruição de células mediado por meso-tetramesitylporfirina, octaetilporfirina, octaetilporfirina de vanadil e luz visível. Eclet. Quím., São Paulo, v. 30, n. 1, 2005.

10- RIBEIRO, J. N., et al. Envolvimento da mitocôndria em apoptose de células cancerígenas induzida por terapia fotodinâmica. J. Bras. Patol. Med. Lab., Rio de Janeiro, v. 40, n. 6, 2004.

11- ROSENTHAL, Robert C.. Segredos em oncologia veterinaria: Respostas necessarias ao dia-a-dia em rounds, na clinica, em exames orais e escritos. São 
Paulo: Artmed, p. 127-129, 2001.

12- SCOTT, Danny W. Muller \& Kirk - Dermatologia de Pequenos Animais. $5^{\mathrm{a} e d .}$ Ed. Interlivros Edições Ltda. Rio de Janeiro, RJ, 1995. p.906-907.

13- SIBATA, C.H. et al. Photodynamic therapy: a new concept in medical treatment. Braz J Med Biol Res., Ribeirão Preto, v. 33, n. 8, 2000.

14- SIMPLICIO, Fernanda Ibanez, et al. Terapia fotodinâmica: aspectos farmacológicos, aplicações e avanços recentes no desenvolvimento de medicamentos. Quím. Nova., São Paulo, v. 25, n. 5, 2002.

15- SLATTER, Douglas. Manual de cirurgia de pequenos animais. 2.ed. Ed. Manole Ltda. São Paulo, SP, 1998. p.774-779.

16- VERGNON, J-M., et al. Place of cryotherapy, brachytherapy and photodynamic therapy in therapeutic bronchoscopy of lung cancers. The European Respiratory Journal, Sheffield, Inglaterra, GB , v.28 , n.1 , , p. 200-218, jul.2006.

17- YAMADA JÚNIOR, A. M., et al. O emprego da terapia fotodinâmica (PDT) na redução bacteriana em periodontia e implantodontia. Rgo, Porto Alegre, v.52, n.3 , p. 207-210, jul/ago/set. 2004. 